in vivo $34: 1759-1764(2020)$

doi:10.21873/invivo.11969

\title{
Interaction of Interleukin-16 Genotypes With Betel Quid Chewing Behavior on Oral Cancer in Taiwan
}

\author{
LIANG-CHUN SHIH ${ }^{1,2,3^{*}}$, WEN-SHIN CHANG ${ }^{1,2^{*}}$, HSU-TUNG LEE $^{4,5^{*}}$, YUN-CHI WANG $^{1,2}$, \\ ZHI-HONG WANG ${ }^{6}$, CHE-YI CHAO ${ }^{6}$, CHIEN-CHIH YU ${ }^{2,7}$, HUI-YI LIN ${ }^{7}$, TE-CHUN SHEN ${ }^{2}$, \\ CHIEN-CHUNG KUO ${ }^{2}$, CHIA-WEN TSAI ${ }^{1,2}$ and DA-TIAN BAU ${ }^{1,2,8}$ \\ ${ }^{1}$ Graduate Institute of Biomedical Sciences, China Medical University, Taichung, Taiwan, R.O.C.; \\ ${ }^{2}$ Terry Fox Cancer Research Laboratory, Department of Medical Research, \\ China Medical University Hospital, Taichung, Taiwan, R.O.C.; \\ ${ }^{3}$ Department of Otolaryngology, China Medical University Hospital, Taichung, Taiwan, R.O.C.; \\ ${ }^{4}$ Cancer Prevention Center, Taichung Veterans General Hospital, Taichung, Taiwan, R.O.C.; \\ ${ }^{5}$ Department of Neurosurgery, Neurological Institute, \\ Taichung Veterans General Hospital, Taichung, Taiwan, R.O.C.; \\ ${ }^{6}$ Department of Food Nutrition and Health Biotechnology, Asia University, Taichung, Taiwan, R.O.C.; \\ ${ }^{7}$ School of Pharmacy, China Medical University, Taichung, Taiwan, R.O.C.; \\ ${ }^{8}$ Department of Bioinformatics and Medical Engineering, Asia University, Taichung, Taiwan, R.O.C.
}

\begin{abstract}
Background/Aim: Interleukin-16 (IL-16) is reported to play an important role in inflammation, carcinogenesis and tumoricidal processes, however, the contribution of IL-16 genotype to oral carcinogenesis is still largely unrevealed. Thus, the study aimed to investigate the contribution of IL-16 genotypes to Taiwan oral cancer risk. Materials and Methods: The genotypes of IL-16 rs4778889, rs 11556218, and rs4072111 were revealed among 958 oral cancer cases and 958 control subjects by polymerase chain reaction-based restriction fragment length polymorphism (PCR-RFLP). Results: First, the distributions of genotypic $(p=0.0004)$ and allelic $(p=0.0001)$ frequencies of $I L-16$ rs 11556218 were significantly different between the case and control groups. In detail, the frequencies of $I L-16$ rs $11556218 \mathrm{TG}$ and $G G$ were 28.1 and $5.8 \%$, respectively, among oral cancer patients, significantly higher compared to those among controls (25.0\% and $2.7 \%$, respectively).
\end{abstract}

This article is freely accessible online.

*These Authors contributed equally to this study.

Correspondence to: Da-Tian Bau, Chia-Wen Tsai and Chien-Chung Kuo, Terry Fox Cancer Research Laboratory, Department of Medical Research, China Medical University Hospital, 2 Yuh-Der Road, Taichung, 404 Taiwan, R.O.C. Tel: +886 422053366 ext. 5805, e-mail: datian@mail.cmuh.org.tw; artbau2@gmail.com

Key Words: Betel quid chewing, genotype, interleukin-16, oral cancer, single nucleotide polymorphism, Taiwan.
Second, no difference was observed regarding IL-16 rs4778889 or IL-16 rs4072111. Last, there was a synergistic effect of betel quid chewing behavior and risky IL-16 rs 11556218 genotype on oral cancer risk. Conclusion: The study indicates that the IL-16 rs11556218 G allele synergistically interacts with betel quid chewing behavior, contributing to increased risk of oral cancer in Taiwanese.

From the viewpoint of epidemiology, oral cancer is the tenth most commonly diagnosed cancer worldwide, with the highest incidence density in Taiwan (1). According to the updated annual report from the Taiwan government, oral cancer is the fourth cause of cancer-related deaths among males in Taiwan and the fifth among all Taiwanese (2). For many years, betel quid chewing habit has been identified as the most effective environmental contributor to oral cancer risk for Taiwanese (3). Although the surgery, therapy and medical caring services for oral cancer have made rapid progress during the past decade, the prevalence and death rate of oral cancer are still very high in Taiwan. Thus, early detection and prediction biomarkers for oral cancer risk are in urgent need.

Interleukin-16 (IL-16) is encoded by the $I L-16$ gene located on chromosome 15q26.3, composed of 631 amino acids and cleaved by caspase 3 to the active IL- 16 protein, comprising the 121 amino acid C-terminal (4-6). IL-16 is in charge of activating several types of cells, including CD4+ $\mathrm{T}$ cells, monocytes, macrophages, eosinophils, and dendritic cells, and promotes the secretion of inflammatory cytokines, such as IL-1 $\square$ (7), TNF- $\square$, and IL-15 (8). Interestingly, a 
significant increase in the IL-16 expression level has been widely reported in a panel of cancer tissues (9-15). In 2008, a genome-wide association study reported that $I L-16$ polymorphic differences in people may serve as a practical marker for prostate cancer prediction (16). In the next year, Thomas and his colleagues reported that the frequency of the $\mathrm{G}$ allele in $I L-16$ rs 11556218 polymorphism can serve as a risk predictor for colorectal and gastric cancer (15), with no gender prevalence in any of them. At the same time, it was shown that women more frequently carrying the $\mathrm{T}$ allele in $I L-16$ rs4072111 had a lower risk of colorectal and gastric cancer compared to those carrying the $C$ allele more (15).

Despite the significant involvement of $I L-16$ in cancer etiology and pathogenesis, no investigation about the contribution of $I L-16$ genotypes or phenotypes to oral cancer risk has been performed. Based on what has been published, we are interested to assess whether rs4778889 $\mathrm{T} / \mathrm{C}$, rs11556218 T/G and rs4072111 C/T polymorphisms of $I L-16$ are associated with a higher risk of oral cancer in Taiwan. In addition, we examined the joint effect of betel quid chewing status and particular $I L-16$ polymorphisms on oral cancer risk.

\section{Materials and Methods}

Investigated controls and cases. Briefly, 958 oral cancer cases were recruited at the China Medical University Hospital in central Taiwan (17-19). The demographic indexes of the oral cancer patients, including their histological details, were all graded and defined by expert surgeons. Each of the cancer patients voluntarily provided 5 $\mathrm{ml}$ of their peripheral blood and completed a questionnaire that focused on medical history and habits, such as diet, alcohol consumption, areca chewing and smoking. Then, the same number of healthy individuals with no cancer were selected to form the control group matched by age and gender after an initial random sampling from the Health Examination Cohort pool. They too contributed blood and completed the same questionnaire as the cancer patients. Self-reported habits, such as alcohol consumption, areca chewing and smoking were evaluated and classified as categorical variables. The personal frequencies of these personal behaviors, including alcohol consumption, areca chewing and smoking, as more than twice a week for years was recorded as a status/habit. These factors were recorded and are concisely summarized in Table I. The male versus female ratio was $76 \%$ to $24 \%$ in both control and oral cancer patient groups, perfectly matched with one another. The prognosis status of all the oral cancer patients, such as recurrence, metastasis and survival, were followed at least twice per year after their surgery. The mean age of the patients and the controls was $56.4(\mathrm{SD}=7.5)$ and 56.8 $(\mathrm{SD}=8.7$ ) years, showing that the matching was successful, causing a non-significantly differential distribution between the case and control groups. The study was reviewed and approved by the Institutional Review Board (DMR101-IRB1-306).

Oral cancer IL-16 genotyping methodology. Genomic DNA from the peripheral blood leucocytes of all oral cancer patients and matched controls were extracted using the QIAamp Blood Mini Kit (Blossom, Taipei, Taiwan) and further processed in typical
Table I. Selected characteristics of the 958 patients with oral cancer and 958 controls.

\begin{tabular}{lccc}
\hline Characteristics & $\begin{array}{c}\text { Controls } \\
(\mathrm{n}=958)\end{array}$ & $\begin{array}{c}\text { Cases } \\
(\mathrm{n}=958)\end{array}$ & $p$-Value \\
\hline Age (years) & $56.8 \pm 8.7$ & $56.4 \pm 7.5$ & $0.3755^{\mathrm{a}}$ \\
Gender, $\mathrm{n}(\%)$ & $728(76.0 \%)$ & $728(76.0 \%)$ & $1.0000^{\mathrm{b}}$ \\
$\quad$ Male & $230(24.0 \%)$ & $230(24.0 \%)$ & \\
$\quad$ Female & & & \\
Personal habits, $\mathrm{n}(\%)$ & $668(69.7 \%)$ & $718(74.9 \%)$ & $\mathbf{0 . 0 1 0 7}^{\mathrm{b}}$ \\
$\quad$ Cigarette smoking & $642(67.0 \%)$ & $684(71.4 \%)$ & $\mathbf{0 . 0 3 7 7}^{\mathrm{b}}$ \\
Alcohol drinking & $508(53.0 \%)$ & $773(80.7 \%)$ & $<\mathbf{0 . 0 0 0 1}$ \\
$\quad$ Betel quid chewing & & $397(41.4 \%)$ & \\
Primary tumor site, $\mathrm{n}(\%)$ & & $356(37.2 \%)$ & \\
$\quad$ Tongue & & $39(4.1 \%)$ & \\
Buccal mucosa & & $33(3.4 \%)$ & \\
Mouth floor & & $29(3.0 \%)$ & \\
Retromolar trigone & & $27(2.8 \%)$ & \\
Alveolar ridge & & $39(4.1 \%)$ & \\
Palate & & $38(4.0 \%)$ & \\
Lip & & & \\
Other & & &
\end{tabular}

SD: Standard deviation; aBased on Student's $t$-test; bBased on chisquare test. Significant $p$-Values $(p<0.05)$ are shown in bold.

polymerase chain reaction (PCR) processes as in our previous papers (20-22). The sequences of designed forward and reverse primers, corresponding restriction enzymes (New England BioLabs, Ipswich, MA, USA) and sizes of PCR products after enzyme digestion for oral cancer $I L-16$ genotyping identification are shown in Table II. The PCR cycling were set as: i) one cycle at $94^{\circ} \mathrm{C}$ for 5 min, ii) 35 cycles of $94^{\circ} \mathrm{C}$ for $30 \mathrm{~s}$, iii) $55^{\circ} \mathrm{C}$ for $30 \mathrm{~s}$, iv) $72^{\circ} \mathrm{C}$ for $30 \mathrm{~s}$, and v) a final extension at $72^{\circ} \mathrm{C}$ for $10 \mathrm{~min}$. The PCR products were run on a $3 \%$ agarose gel on 100 Volt for $20 \mathrm{~min}$. The genotyping procedure was performed by three researchers independently and blindly. The repeated results from different researchers within each subject were perfectly consistent.

Statistical analyses. First, the Student's $t$-test was used to compare the distribution of ages between the two groups. Second, Pearson's chi-square test was applied to compare the distribution of the $I L-16$ rs4778889, rs11556218 and rs4072111 genotypes among the subgroups, and to also examine the possible interaction among the indices of interest. Last, the association between the $I L-16$ rs 4778889 , rs 11556218 or rs4072111 polymorphisms and oral cancer risk were estimated using computing odds ratios (ORs) and their $95 \%$ confidence intervals (CIs) using logistic regression analysis. Any difference with the outcome of $p<0.05$ was considered statistically significant.

\section{Results}

Table I summarizes the demographic characteristics of the 1,916 recruited subjects (958 oral cancer cases and 958 noncancer healthy controls) of this study. There is no significant difference with respect to age and gender, while smoking, alcohol consumption and betel quid chewing all have 
Table II. Sequences of the designed primers, corresponding restriction enzymes and fragments identifications for genotyping of IL-16 rs4778889, rs11556218 and rs4072111.

\begin{tabular}{llcc}
\hline Polymorphic site & 5' to 3' primer sequences & Restriction enzymes & $\begin{array}{c}\text { Allelic type and product } \\
\text { size after digestion (bp) }\end{array}$ \\
\hline rs4778889 & CTCCACACTCAAAGCCCTTT & Ahd I & T: 280 \\
rs11556218 & CCATGTCAAAACGGTAGCCT & Nde I $: 246+34$ \\
rs4072111 & GCTCAGGTTCACAGAGTGTT & & G: 171 \\
& TGTGACAATCACAGCTTGCC & BsmA I & C: $164+24$ \\
& CACTGTGATCCCGGTCCAGT & & T: $140+24$ \\
\hline
\end{tabular}

Table III. Distribution of IL-16 rs4778889, rs11556218 and rs4072111 genotypes among the 958 patients with oral cancer and 958 controls.

\begin{tabular}{|c|c|c|c|c|c|c|}
\hline \multirow[t]{2}{*}{ Genotype } & \multicolumn{2}{|c|}{ Patients } & \multicolumn{2}{|c|}{ Controls } & \multirow[t]{2}{*}{ OR $(95 \% \mathrm{CI})$} & \multirow[t]{2}{*}{$p$-Value ${ }^{\mathrm{a}}$} \\
\hline & $\mathrm{n}$ & $\%$ & $\mathrm{n}$ & $\%$ & & \\
\hline \multicolumn{7}{|l|}{ rs4778889 } \\
\hline $\mathrm{TT}$ & 633 & $66.1 \%$ & 621 & $64.8 \%$ & 1.00 (reference) & \\
\hline $\mathrm{CT}$ & 293 & $30.6 \%$ & 302 & $31.5 \%$ & $0.95(0.78-1.16)$ & 0.6198 \\
\hline $\mathrm{CC}$ & 32 & $3.3 \%$ & 35 & $3.7 \%$ & $0.90(0.55-1.47)$ & 0.6647 \\
\hline $\mathrm{CT}+\mathrm{CC}$ & 325 & $33.9 \%$ & 337 & $35.2 \%$ & $0.95(0.78-1.14)$ & 0.5643 \\
\hline $\begin{array}{l}P_{\text {trend }} \\
\text { rs } 11556218\end{array}$ & & & & & & 0.8248 \\
\hline $\mathrm{TT}$ & 633 & $66.1 \%$ & 693 & $72.3 \%$ & 1.00 (reference) & \\
\hline TG & 269 & $28.1 \%$ & 239 & $25.0 \%$ & $1.23(1.00-1.51)$ & $0.0456 *$ \\
\hline GG & 56 & $5.8 \%$ & 26 & $2.7 \%$ & $2.36(1.46-3.80)$ & $0.0003 *$ \\
\hline $\mathrm{TG}+\mathrm{GG}$ & 325 & $33.9 \%$ & 265 & $27.7 \%$ & $1.34(1.11-1.63)$ & $0.0030 *$ \\
\hline $\begin{array}{c}P_{\text {trend }} \\
\text { rs } 4072111\end{array}$ & & & & & & $0.0004 *$ \\
\hline $\mathrm{CC}$ & 588 & $61.4 \%$ & 571 & $59.6 \%$ & 1.00 (reference) & \\
\hline $\mathrm{CT}$ & 332 & $34.7 \%$ & 346 & $36.1 \%$ & $0.93(0.77-1.13)$ & 0.4651 \\
\hline $\mathrm{TT}$ & 38 & $3.9 \%$ & 41 & $4.3 \%$ & $0.90(0.57-1.42)$ & 0.6507 \\
\hline $\mathrm{CT}+\mathrm{TT}$ & 370 & $38.6 \%$ & 387 & $40.4 \%$ & $0.93(0.77-1.12)$ & 0.4269 \\
\hline$P_{\text {trend }}$ & & & & & & 0.7217 \\
\hline
\end{tabular}

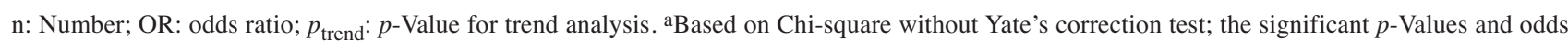
ratios are bolded and marked with a star.

different distribution between the oral cancer and control cohorts. These differences suggest that smoking, alcohol drinking and betel quid chewing are all risk factors for oral cancer in Taiwan (Table I). With regard to pathological identification, the major tumor sites of oral cancer occurred in the tongue (41.4\%) and buccal mucosa (37.2\%) (Table I).

In Table III, we have calculated the distributions of genotypic frequencies of the three IL-16 SNPs (rs4778889, rs11556218 and rs4072111) for all the 1916 investigated subjects. First, the allelic frequencies in the rs4778889, rs11556218 and rs4072111 of the control group agreed well with the Hardy-Weinberg equilibrium (all $p>0.05$ ). Second, in $I L-16$ rs4778889, there was no significant difference between the case and control groups concerning the frequency of TT, CT and CC (Table III, top panel, $p$ for trend $>0.05$ ). Third, there was a noticeably significant difference in the distribution of $I L-16$ rs11556218 genotypic frequencies with regards to the TT, TG and GG genotypes between the case and control groups (Table III, middle panel, $p$ for trend=0.0004). Furthermore, we found that TG, GG and TG+GG genotypes were differentially distributed between the case and control groups, compared to that of the wild-type TT genotype (Table III, middle panel, all $p<0.05$ and OR $>1.00$ ). Last, concerning $I L-16$ rs4072111, there was no significant difference between the case and control groups with regards to the frequency of the CC, CT and TT genotypes (Table III, bottom panel, $p$ for trend $>0.05$ ). Overall, it seems that only the $I L-16$ rs11556218 polymorphism, and not $I L-16$ rs4778889 or rs4072111, can serve as a predictive biomarker for higher risk of oral cancer in Taiwan. 
in vivo $34: 1759-1764(2020)$

Table IV. Distributions of IL-16 rs4778889, rs11556218 and rs4072111 allelic frequencies among the 958 patients with oral cancer and 958 controls.

\begin{tabular}{|c|c|c|c|c|c|c|}
\hline Allele & Patients & $\%$ & Controls & $\%$ & OR $(95 \% \mathrm{CI})$ & $p$-Value ${ }^{\mathrm{a}}$ \\
\hline \multicolumn{7}{|l|}{ rs4778889 } \\
\hline Allele T & 1559 & $81.4 \%$ & 1544 & $80.6 \%$ & 1.00 (reference) & \\
\hline Allele C & 357 & $18.6 \%$ & 372 & $19.4 \%$ & $0.95(0.81-1.12)$ & 0.5370 \\
\hline \multicolumn{7}{|l|}{ rs11556218 } \\
\hline Allele T & 1535 & $80.1 \%$ & 1625 & $84.8 \%$ & 1.00 (reference) & \\
\hline Allele G & 381 & $19.9 \%$ & 291 & $15.2 \%$ & $1.39(1.17-1.64)$ & 0.0001* \\
\hline \multicolumn{7}{|l|}{ rs 4072111} \\
\hline Allele C & 1508 & $78.7 \%$ & 1488 & $77.7 \%$ & 1.00 (reference) & \\
\hline Allele T & 408 & $21.3 \%$ & 428 & $22.3 \%$ & $0.94(0.81-1.10)$ & 0.4340 \\
\hline
\end{tabular}

n: Number; OR: odds ratio; CI: confidence interval; ${ }^{a}$ Based on Chi-square without Yate's correction test; the significant $p$-Value and odds ratio are bolded and marked with a star.

To validate the interesting findings presented in Table III, we also examined the distribution of the allelic frequencies in $I L-16$ rs4778889, rs11556218 and rs4072111 in Table IV. In agreement with the findings in Table III, the variant $G$ allele in $I L-16$ rs 11556218 was associated with a significantly elevated oral cancer risk, compared to the wild-type allele $\mathrm{T}$ $(\mathrm{OR}=1.39,95 \% \mathrm{CI}=1.17-1.64, p=0.0001)$ (Table IV, middle panel). In detail, the frequencies of the $\mathrm{T}$ and $\mathrm{G}$ alleles of $I L$ 16 rs 11556218 were $80.1 \%$ and $19.9 \%$ among the oral cancer patients, respectively, and $84.8 \%$ and $15.2 \%$, respectively, among the non-cancer age- and gender-matched healthy controls (Table IV, middle panel). On the contrary, neither the variant $\mathrm{C}$ allele of $I L-16$ rs4778889 nor the variant $\mathrm{T}$ allele of $I L-16$ rs4072111 were associated with and altered oral cancer risk (Table IV, top and bottom panels, respectively).

Since oral cancer can be related with the consumption of betel quid chewing in Taiwan, we were very interested in the interaction between the genotype of $I L-16$ rs11556218 with betel quid chewing behavior and whether such a combination poses an even higher risk for oral cancer. The joint effect of $I L-16$ rs 11556218 with betel quid chewing habit on oral cancer is shown in Table V. All oral cancer patients and ageand gender-matched controls were stratified according to whether they chew betel quid and their $I L-16$ rs11556218 genotypes. Interestingly, the results showed that there was no higher risk for non-chewers (Table V, top panel); however, there was a significantly elevated oral cancer risk for the betel quid chewers with a variant TG or GG genotypes in $I L-16$ rs11556218 ( $p=0.0013$ ) (Table V, bottom panel).

\section{Discussion}

In the current study, we examined the contribution of $I L-16$ genotypes to elevated oral cancer risk among an extremely large population of Taiwanese, containing 958 oral cancer patients and 958 age-, gender-matched healthy controls. The highlight results
Table V. Distribution of IL-16 rs11556218 genotypes among the 958 patients with oral cancer and 958 controls after stratification by betel quid chewing status.

\begin{tabular}{lcccc}
\hline BQ status & \multicolumn{2}{c}{$I L-16$ rs11556218 genotype } & \\
\cline { 2 - 4 } & TT (\%) & TG (\%) & GG (\%) & $p$-Value $^{\mathrm{a}}$ \\
\hline Chewers & & & & \\
$\quad \begin{array}{l}\text { Controls } \\
\text { Patients }\end{array}$ & $373(73.4 \%)$ & $123(24.2 \%)$ & $12(2.4 \%)$ & \\
Non-chewers & $510(66.0 \%)$ & $216(27.9 \%)$ & $47(6.1 \%)$ & 0.3827 \\
$\quad$ Controls & $320(71.1 \%)$ & $116(25.8 \%)$ & $14(3.1 \%)$ & \\
Patients & $123(66.5 \%)$ & $53(28.6 \%)$ & $9(4.9 \%)$ & $\mathbf{0 . 0 0 1 3}^{*}$ \\
\hline
\end{tabular}

BQ: Betel quid. aBased on Chi-square without Yate's correction test; the significant $p$-Value and odds ratio are bolded and marked with a star.

showed that $I L-16$ rs $11556218 \mathrm{G}$ carriers were of a statistically higher risk for oral cancer, while this significance was not found for the $I L-16$ rs4778889 or $I L-16$ rs4072111 alleles. The $I L-16$ rs 11556218 is a polymorphic site in charge of a missense coding from the wild-type Asn (T) to the variant Lys (G). Notably, $I L$ 16 rs 11556218 TG and GG genotypes could potentially serve as novel genomic biomarkers for predicting increased oral cancer risk in Taiwan, where the density of oral cancer is the highest in the world. In 2009, the serum levels of $I L-16$ were reported to be higher in colorectal cancer and gastric cancer patients; however, no significant genotype-phenotype correlation between $I L-16$ rs11556218 polymorphisms and serum levels of IL-16 was observed in that study (15). There is no literature available about the expression levels of IL-16 among oral cancer patients. Future studies on the specific genotype-phenotype correlation of IL-16 among Taiwanese will provide useful information for predicting those at higher risk.

In our study, we further found that the variant genotypes of $I L-16$ rs11556218 were associated with an elevated oral cancer risk in the group of betel quid chewers, but not in the 
non-chewers group. These novel findings strongly encourage additional investigations regarding the functional phenotypes of $I L-16$ rs 11556218 and their involvement in oral cancer etiology, as well as the interaction between $I L-16$ rs 11556218 and betel quid chewing.

In the current study, we proposed the variant TG and GG genotypes at $I L-16$ rs11556218 can serve as practical biomarkers for oral cancer risk prediction in Taiwan. An elevated risk has also been found in several other types of cancer, including nasopharyngeal carcinoma (another important head and neck cancer) (23), gastric cancer (15), hepatocellular carcinoma (24) and colorectal cancer (15) in other populations. It is of great interest for us to investigate whether $I L-16$ rs 11556218 can serve as practical biomarkers for these types of cancer in Taiwan. As for $I L-16$ rs4778889, it has been found that the C allele of $I L-16$ rs4778889 is associated with the risk of renal cell carcinoma (25), especially among Asian ethnicities (26); however, this polymorphic site is not a contributor to oral cancer risk prediction.

From the viewpoint of oral cancer genomics, there are several biomarkers in the fields of DNA repair activity (27, $28)$, extracellular matrix regulation $(17,18)$, antioxidant capacity $(28,29)$, cell viability (19). All these, in addition to the immune-responsiveness studied here, are contributors to differential susceptibility of individual patients. These markers can potentially be correlated with information from the systemic recordings found in clinicopathological databases of the oral cancer patients for the prediction of prognosis outcomes, such as survival (30) and metastasis (31). Additional genotype-phenotype correlation studies can help in revealing the biological meanings of these genomic markers, extending our understanding of the etiology of each oral cancer patient, leading to personalized therapeutic options.

In conclusion, the study provides solid evidence that the TG and GG genotypes of IL-16 rs11556218 are associated with increased oral cancer risk among Taiwanese, especially those with betel quid chewing habit. Further studies with larger subjects in diverse ethnic populations are needed to verify our findings. The genotype-phenotype correlation investigations would be very valuable to reveal the contribution of IL-16 to oral carcinogenesis.

\section{Conflicts of Interest}

All Authors declare no conflicts of interest regarding this study.

\section{Authors' Contributions}

Research design was done by SLC, TCW, and LHT. Patient and questionnaire summaries were provided by SLC, STC, and LHT. Experimental work was done by WYC, CWS, and WZH. Statistical analysis was done by CCY, YCC, and LHY. KCC, TCW, and BDT wrote the manuscript, whereas BDT, CWS, and TCW reviewed it and are responsible for the revision.

\section{Acknowledgements}

The Authors are grateful to the Tissue-bank of China Medical University Hospital and doctors/nurses under Prof. Tsai MH's leadership for their excellent sample collection and survey assistance. The technical assistance from Si-Hua Chen, Yu-Hsin Lin, Yi-Ru Huang and Yu-Chen Hsiau, the consultants of statistical analysis from Cheng-Li Lin were also very helpful for the manuscript preparation. This study was supported mainly by research grants from China Medical University Hospital (DMR-108-BC-1) and partially by Taichung Veterans General Hospital (TCVGH-1084906C).

\section{References}

1 Torre LA, Bray F, Siegel RL, Ferlay J, Lortet-Tieulent J and Jemal A: Global cancer statistics, 2012. CA Cancer J Clin 65(2): 87-108, 2015. PMID: 25651787. DOI: 10.3322/caac. 21262

2 Taiwan Ministry of Health and Welfare Clinical Trial and Research Center of Excellence: Cancer Registration Annual Report. Available at: https://www.hpa.gov.tw/Pages/List.aspx? nodeid $=269$ [Last accessed on March 17th, 2020]

3 Ko YC, Huang YL, Lee CH, Chen MJ, Lin LM and Tsai CC: Betel quid chewing, cigarette smoking and alcohol consumption related to oral cancer in Taiwan. J Oral Pathol Med 24(10): 450453, 1995. PMID: 8600280. DOI: 10.1111/j.1600-0714.1995. tb01132.x

4 Baier M, Bannert N, Werner A, Lang K and Kurth R: Molecular cloning, sequence, expression, and processing of the interleukin 16 precursor. Proc Natl Acad Sci USA 94(10): 5273-5277, 1997. PMID: 9144227. DOI: 10.1073/pnas.94.10.5273

5 Drwinga HL, Toji LH, Kim CH, Greene AE and Mulivor RA: NIGMS human/rodent somatic cell hybrid mapping panels 1 and 2. Genomics 16(2): 311-314, 1993. PMID: 8314568. DOI: 10.1006/geno.1993.1190

6 Zhang Y, Center DM, Wu DM, Cruikshank WW, Yuan J, Andrews DW and Kornfeld H: Processing and activation of prointerleukin-16 by caspase-3. J Biol Chem 273(2): 1144-1149, 1998. PMID: 9422780 . DOI: $10.1074 /$ jbc.273.2.1144

7 Mathy NL, Scheuer W, Lanzendorfer M, Honold K, Ambrosius D, Norley $\mathrm{S}$ and Kurth R: Interleukin-16 stimulates the expression and production of pro-inflammatory cytokines by human monocytes. Immunology 100(1): 63-69, 2000. PMID: 10809960. DOI: 10.1046/j.1365-2567.2000.00997.x

8 Zheng Y, Cao KY, Ng SP, Chua DT, Sham JS, Kwong DL, Ng $\mathrm{MH}, \mathrm{Lu} \mathrm{L}$ and Zheng BJ: Complementary activation of peripheral natural killer cell immunity in nasopharyngeal carcinoma. Cancer Sci 97(9): 912-919, 2006. PMID: 16805822. DOI: $10.1111 /$ j.1349-7006.2006.00252.x

9 Kovacs E: The serum levels of IL-12 and IL-16 in cancer patients. Relation to the tumour stage and previous therapy. Biomed Pharmacother 55(2): 111-116, 2001. PMID: 11293814. DOI: $10.1016 / \mathrm{s} 0753-3322(00) 00023-8$

10 Liebrich M, Guo LH, Schluesener HJ, Schwab JM, Dietz K, Will $\mathrm{BE}$ and Meyermann R: Expression of interleukin-16 by tumorassociated macrophages/activated microglia in high-grade astrocytic brain tumors. Arch Immunol Ther Exp (Warsz) 55(1): 41-47, 2007. PMID: 17221335. DOI: 10.1007/s00005-007-0003-0

11 Koike M, Sekigawa I, Okada M, Matsumoto M, Iida N, Hashimoto $\mathrm{H}$ and Oshimi K: Relationship between CD4(+)/CD8(+) T cell 
ratio and $\mathrm{T}$ cell activation in multiple myeloma: reference to IL16. Leuk Res 26(8): 705-711, 2002. PMID: 12191564. DOI: 10.1016/s0145-2126(01)00192-8

12 Alexandrakis MG, Passam FH, Kyriakou DS, Christophoridou AV, Perisinakis K, Hatzivasili A, Foudoulakis A and Castanas E: Serum level of interleukin-16 in multiple myeloma patients and its relationship to disease activity. Am J Hematol 75(2): 101-106, 2004. PMID: 14755377. DOI: 10.1002/ajh.10444

13 Passam FH, Sfiridaki A, Pappa C, Kyriakou D, Petreli E, Roussou PA and Alexandrakis MG: Angiogenesis-related growth factors and cytokines in the serum of patients with B nonHodgkin lymphoma; relation to clinical features and response to treatment. Int J Lab Hematol 30(1): 17-25, 2008. PMID: 18190463. DOI: 10.1111/j.1365-2257.2006.00890.x

14 Blaschke V, Reich K, Middel P, Letschert M, Sachse F, Harwix $\mathrm{S}$ and Neumann C: Expression of the CD4+ cell-specific chemoattractant interleukin-16 in mycosis fungoides. J Invest Dermatol 113(4): 658-663, 1999. PMID: 10504456. DOI: 10.1046/j.1523-1747.1999.00717.x

15 Gao LB, Rao L, Wang YY, Liang WB, Li C, Xue H, Zhou B, Sun H, Li Y, Lv ML, Du XJ and Zhang L: The association of interleukin-16 polymorphisms with IL-16 serum levels and risk of colorectal and gastric cancer. Carcinogenesis 30(2): 295-299, 2009. PMID: 19073878. DOI: $10.1093 /$ carcin/bgn281

16 Thomas G, Jacobs KB, Yeager M, Kraft P, Wacholder S, Orr N, Yu K, Chatterjee N, Welch R, Hutchinson A, Crenshaw A, Cancel-Tassin G, Staats BJ, Wang Z, Gonzalez-Bosquet J, Fang J, Deng X, Berndt SI, Calle EE, Feigelson HS, Thun MJ, Rodriguez C, Albanes D, Virtamo J, Weinstein S, Schumacher FR, Giovannucci E, Willett WC, Cussenot O, Valeri A, Andriole GL, Crawford ED, Tucker M, Gerhard DS, Fraumeni JF, Jr., Hoover R, Hayes RB, Hunter DJ and Chanock SJ: Multiple loci identified in a genome-wide association study of prostate cancer. Nat Genet 4O(3): 310-315, 2008. PMID: 18264096. DOI: 10.1038/ng.91

17 Shih LC, Li CH, Sun KT, Chen LY, Hsu CL, Hung YW, Wu CN, Hsia TC, Shen TC, Chang WS, Shih TC, Tsai CW and Bau DT: Association of matrix metalloproteinase-7 genotypes to the risk of oral cancer in Taiwan. Anticancer Res 38(4): 2087-2092, 2018. PMID: 29599326. DOI: 10.21873/anticanres.12448

18 Tsai CW, Hsu HM, Wang YC, Chang WS, Shih LC, Sun KT, Hung YW, Yang YC, Gong CL and Bau DT: Contribution of MMP2 promoter genotypes to oral cancer susceptibility, recurrence and metastasis in Taiwan. Anticancer Res 38(12): 6821-6826, 2018. PMID: 30504396. DOI: 10.21873/anticanres. 13055

19 Shih LC, Tsai CW, Sun KT, Hsu HM, Shen TC, Tsai YT, Chang WS, Lin ML, Wang YC, Gong CL and Bau DT: Association of caspase-8 genotypes with oral cancer risk in Taiwan. In Vivo 33(4): 1151-1156, 2019. PMID: 31280204. DOI: 10.21873/ invivo. 11585

20 Hsu SW, Gong CL, Hsu HM, Chao CC, Wang YC, Chang WS, Tsai YT, Shih LC, Tsai CW and Bau DT: Contribution of matrix metalloproteinase-2 promoter genotypes to nasopharyngeal cancer susceptibility and metastasis in Taiwan. Cancer Genomics Proteomics 16(4): 287-292, 2019. PMID: 31243109. DOI: $10.21873 / \operatorname{cgp} .20133$
21 Pei JS, Chang WS, Hsu PC, Chen CC, Chin YT, Huang TL, Hsu YN, Kuo CC, Wang YC, Tsai CW, Gong CL and Bau DT: Significant association between the MiR146a genotypes and susceptibility to childhood acute lymphoblastic leukemia in Taiwan. Cancer Genomics Proteomics 17(2): 175-180, 2020. PMID: 32108040. DOI: $10.21873 / \mathrm{cgp} .20178$

22 Hu PS, Wang YC, Liao CH, Hsia NY, Wu MF, Yang JS, Yu CC, Chang WS, Bau DT and Tsai CW: The association of MMP7 genotype with pterygium. In Vivo 34(1): 51-56, 2020. PMID: 31882462. DOI: 10.21873/invivo.11744

23 Gao LB, Liang WB, Xue H, Rao L, Pan XM, Lv ML, Bai P, Fang WL, Liu J, Liao $M$ and Zhang L: Genetic polymorphism of interleukin-16 and risk of nasopharyngeal carcinoma. Clin Chim Acta 409(1-2): 132-135, 2009. PMID: 19758567. DOI: 10.1016/j.cca.2009.09.017

24 Li S, Deng Y, Chen ZP, Huang S, Liao XC, Lin LW, Li H, Peng T, Qin X and Zhao JM: Genetic polymorphism of interleukin-16 influences susceptibility to $\mathrm{HBV}$-related hepatocellular carcinoma in a Chinese population. Infect Genet Evol 11(8): 2083-2088, 2011. PMID: 22019522. DOI: 10.1016/j.meegid. 2011.09.025

25 Wang $\mathrm{Z}, \mathrm{Xu} \mathrm{Y}$ and Zhu S: Interleukin-16 rs4778889 polymorphism contributes to the development of renal cell cancer in a Chinese population. Int J Clin Exp Pathol 8(11): 15228-15233, 2015. PMID: 26823871

26 Zhou T, Li H, Xie WJ, Zhong Z, Zhong $\mathrm{H}$ and Lin ZJ: Association of methylenetetrahydrofolate reductase, vitamin D receptor, and interleukin-16 gene polymorphisms with renal cell carcinoma risk. Technol Cancer Res Treat 18: 1533033819859413, 2019. PMID: 31242814. DOI: $10.1177 /$ 1533033819859413

27 Tsai CW, Chang WS, Liu JC, Tsai MH, Lin CC and Bau DT: Contribution of DNA double-strand break repair gene XRCC3 genotypes to oral cancer susceptibility in Taiwan. Anticancer Res 34(6): 2951-2956, 2014. PMID: 24922659.

28 Tsai CW, Tsai MH, Tsou YA, Shih LC, Tseng HC, Chang WS, Ho CY, Lee HZ and Bau DT: The joint effect of smoking and hOGG1 genotype on oral cancer in Taiwan. Anticancer Res 32(9): 3799-3803, 2012. PMID: 22993322.

29 Barroso Duarte EC, Da Silva MS, Gomez MV and Gomez RS: GSTT1 polymorphism and oral leukoplakia. Anticancer Res 26(1A): 427-430, 2006. PMID: 16475728.

30 Suzuki H, Tamaki T, Nishio M, Beppu S, Mukoyama N, Hanai N, Nishikawa D, Koide Y and Hasegawa Y: Peak of standardized uptake value in oral cancer predicts survival adjusting for pathological stage. In Vivo 32(5): 1193-1198, 2018. PMID: 30150443. DOI: 10.21873/invivo.11363

31 Noguti J, De Moura CF, De Jesus GP, Da Silva VH, Hossaka TA, Oshima CT and Ribeiro DA: Metastasis from oral cancer: an overview. Cancer Genomics Proteomics 9(5): 329-335, 2012. PMID: 22990112.

Received March 18, 2020

Revised April 6, 2020

Accepted April 8, 2020 